\title{
BDIA DENTAL SHOWCASE 2015 DELIVERS BUSINESS AND INNOVATION
}

\section{an}

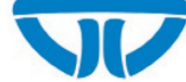

$\mathrm{BD} \mid \mathrm{A}$
BDIA Dental

Showcase, the UK's

leading B2B dental

trade show, opened

its doors to three

days of brisk business

and networking at

Birmingham's NEC

from Thursday 22 to Saturday 24 October.

The exhibition, organised annually by the

British Dental Industry Association (BDIA),

brought together over 330 exhibitors and

the widest selection of dental equipment,

products, services and demonstrations of the

latest techniques for the profession to discover

what's new, meet with product experts and

conduct business deals.

With sponsorships deals in place with the major oral healthcare companies for the next two years, as well as exhibition bookings now being taken up to 2017 in response to exhibitor demand, BDIA Dental Showcase is firmly established as the premier business event for the dental industry.

Visitors to the exhibition had an exceptional opportunity to experience a significant number of innovations firsthand with more dental companies than ever choosing this event to unveil or showcase their latest products to the UK market including Oral-B, Cattani Esam, Ceramic Systems, Cerezen, DMG, KaVo, NSK, Philips, Software of Excellence, TePe, Voco and W\&H to name but a few.
Although overall footfall at the exhibition was a little lower than in previous years it was clear that the event continues to be the place to see what's new, do business and network with colleagues, with plenty of key purchasers and influencers in attendance.

Current ADI President, Philip Friel, said: 'Our programme at Dental Showcase has been a fabulous opportunity to share the advances we have made in implantology. And it was pleasing to see the huge level of interest from dental professionals and be able to answer their questions and provide advice.'

BDIA's Executive Director Tony Reed added: 'Showcase plays a vital role in facilitating business for the sector enabling exhibitors and buyers to meet on a one-toone basis to conduct business.

'Like many others within dentistry I am concerned about the proliferation of events diluting audiences both for exhibitors and the profession. This has refined our audience significantly. A substantial amount of business of mutual benefit has been conducted during Showcase and we are looking forward to another productive event in London next year.'

BDIA Dental Showcase 2016 will be held at ExCeL London from 6-8 October 2016, so make a note in your diary and start planning your visit now!

Delegates can download their CPD certificates from this year's exhibition by visiting www.dentalshowcase.com.

\section{PRACTICE SALES 'STABLE'}

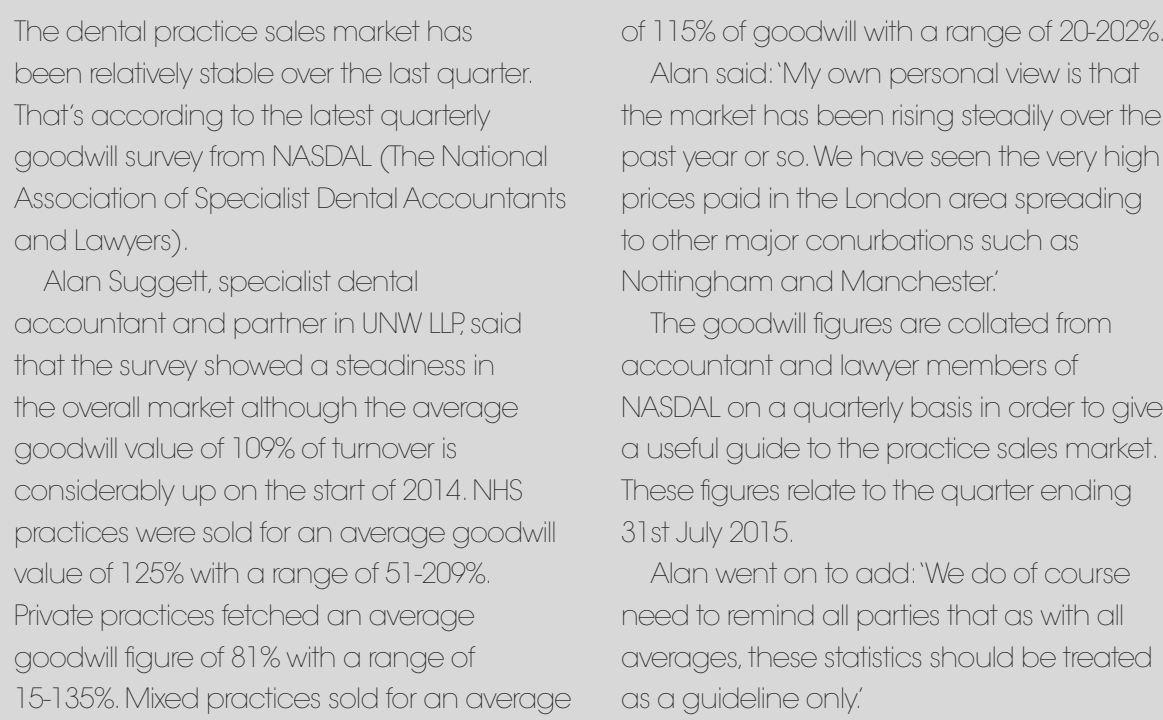

of $175 \%$ of goodwill with a range of $20-202 \%$ Alan said: 'My own personal view is that the market has been rising steadily over the past year or so. We have seen the very high prices paid in the London area spreading to other major conurbations such as

Nottingham and Manchester.

The goodwill figures are collated from accountant and lawyer members of NASDAL on a quarterly basis in order to give a useful guide to the practice sales market These figures relate to the quarter ending 37 st July 2015

Alan went on to add: "We do of course need to remind all parties that as with all averages, these statistics should be treated as a guideline only

\section{BE PREPARED - TAKE THE ORAL CANCER CPD MODULE}

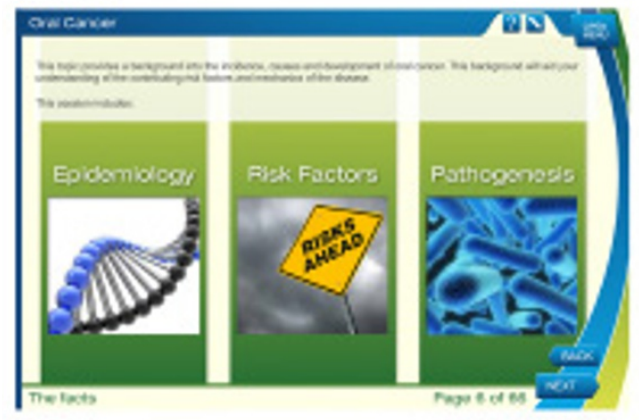

As part of this year's Mouth Cancer

Action Month launch, the Association of Dental Groups (ADG) is pleased to announce the return of the oral cancer CPD module.

Designed by $\{$ my $\}$ dentist, the module reflects the work of the campaign and focuses on the early detection and treatment of the disease.

As early detection of mouth cancer can result in a survival outcome of $90 \%$ the ADG is urging dentists to use this powerful tool to help improve knowledge and raise awareness

Except for a small cost of $£ 25$ plus VAT for those wishing to apply for a CPD certificate - £5 of which will be donated to the British Dental Health Foundation and the Mouth Cancer Action Month campaign - the comprehensive and interactive online module is available for free to all dentists and oral health professionals throughout the UK.

To be part of the movement against oral cancer. contact the ADG today.

To find out more about the free oral cancer training available visit http://www. dentalgroups.co.uk/ mouth_cancer.php.

If you would like to promote your products or services direct to the dental industry in BDJ Team, call Andy May on 02078434785 or emaila.may@nature.com 